\title{
Estratégias no uso de Tecnologias Digitais de Informática e Comunicação (TDICs) e as práticas de ensino supervisionadas
}

\author{
Morgana Schenkel Junqueira ${ }^{1}$, Joslaine Cristina Jeske de Freitas ${ }^{1}$, \\ ${ }^{1}$ Unidade Acadêmica Especial de Ciências Exatas e Tecnológicas \\ Universidade Federal de Goiás (UFG) \\ Caixa Postal 75801-615 - Jataí - GO - Brazil \\ msj11_nana@hotmail.com, joslaine@gmail.com
}

\begin{abstract}
The dynamics created around digital technologies and the Internet have been designed to change education. Thus, there is a real need for teacher professionalization for the use of technologies in this new school culture. The use of Digital Technologies of Communication and Education (TDICs) can improve the pedagogical action, since they insert new devices that facilitate and dynamize the process of teaching learning. In order to understand the importance of TDICs in teacher training, the article presents some questions that aim to discuss the relationship between teacher education and the use of TDICs as a teaching strategy. The results obtained from the definitions of the research questions indicate that the TDICs not only dynamize the pedagogical practice but also favor new perspectives for the construction of knowledge and in the teaching-learning process both in the teacher training and in the intellectual growth of the students.
\end{abstract}

Resumo. As dinâmicas criadas em torno das tecnologias digitais e da Internet vem sendo projetadas visando mudanças na educação. Sendo assim, existe a real necessidade de profissionalização de professores para o uso das tecnologias nesta nova cultura escolar. O uso das Tecnologias Digitais de Comunicação e Educação (TDICs) podem melhorar a ação pedagógica, já que inserem novos dispositivos que facilitam e dinamizam o processo de ensino aprendizagem. Com o objetivo de compreender a importância das TDICs na formação dos professores, o artigo apresenta algumas questões que visam discutir a relação entre a formação docente e o uso das TDICs como estratégia de ensino. Os resultados obtidos a partir da definições das questões de pesquisa indicam que as TDICs não apenas dinamizam a prática pedagógica como também favorecem novas perspectivas para a construção de conhecimento e no processo de ensino-aprendizagem tanto na formação dos docente quanto no crescimento intelectual dos discentes.

\section{Introdução}

A educação e a comunicação como áreas do conhecimento fluem e se atualizam de acordo com as oportunidades oferecidas pelas mais diferenciadas inovações tecnológicas [Nicolau et al. 2018]. Neste contexto, a presença das Tecnologias Digitais de Comunicação e Educação (TDICs) no dia a dia tem alterado visivelmente os meios de comunicação no âmbito da aprendizagem [Xavier 2013]. 
VIII Congresso Brasileiro de Informática na Educação (CBIE 2019)

Anais do XXV Workshop de Informática na Escola (WIE 2019)

A aprendizagem deve estar aliada a construção de novos conhecimentos. Assim, no processo ensino-aprendizagem, o papel do professor deve ser não mais o de ensinar, mas o de orientador da aprendizagem, instigando a curiosidade do aluno [Farias and Dias 2013]. Desta forma, é importante que as tecnologias digitais sejam inseridas na educação de maneira a desenvolver uma nova maneira de ensino utilizando-se meios pedagógicos adequados [Nicolau et al. 2018].

Partindo deste cenário, as TDICs podem ser definidas como um conjunto de recursos tecnológicos, utilizados de forma integrada, com um objetivo comum [Monteiro et al. 2015]. As TDICs são utilizadas das mais diversas formas. Na educação, por exemplo, pode-se citar o processo de ensino aprendizagem, a educação a distância, entre outros, podendo ser definida também como todas as tecnologias que interferem e medeiam os processos informacionais e comunicativos dos seres. Uma das áreas mais favorecidas com as TDICs é a educacional [Pereira and Goncalves 2017].

Diante disso, um novo paradigma está surgindo na educação e o papel do professor, frente às novas tecnologias, será diferente. Com as novas tecnologias pode-se desenvolver um conjunto de atividades com interesse didático-pedagógico, como: intercâmbios de dados científicos e culturais de diversa natureza; produção de texto em língua estrangeira; elaboração de jornais inter-escolas, permitindo desenvolvimento de ambientes de aprendizagem centrados na atividade dos alunos, na importância da interação social e no desenvolvimento de um espírito de colaboração e de autonomia nos alunos [Nunes et al. 2017].

É necessário, sobretudo, que os professores se sintam confortáveis para utilizar esses novos auxiliadores didáticos. Estar confortável significa conhecê-los, dominar os principais procedimentos técnicos para sua utilização, avaliá-los criticamente e criar novas possibilidades pedagógicas, partindo da integração desses meios com o processo de ensino [Monteiro et al. 2015].

Este trabalho tem por intuito apresentar alguns aspectos da relevância do uso de TDICs de ensino-aprendizagem como ferramenta no auxílio da formação inicial de professores em seu uso pedagógico, pretende-se discutir estes aspectos tendo como base a importância da implementação dessas tecnologias no ambiente escolar, sendo estruturado da seguinte forma: a Seção 2 apresenta o conceito do artigo apresentado, a definição das questões de pesquisa acerca do tema para sua fundamentação. A Seção 3 analisa os resultados obtidos com o intuito de responder as questões de pesquisa definidas. Por último, a Seção 4 descreve a conclusão deste trabalho.

\section{Metodologia}

\subsection{Definição das questões de pesquisa}

A questão central que motivou esse trabalho foi: Quais estratégias em TDICs podem ser utilizadas no processo de ensino-aprendizagem para auxiliar na formação inicial de professores para o uso pedagógico?

Sendo assim, foram definidas duas questões de pesquisa:

- Questão 1: Qual o perfil dos professores?

- Questão 2: Quais estratégias utilizando as TDICs podem ser utilizadas para melhorar o processo de ensino-aprendizagem? 
VIII Congresso Brasileiro de Informática na Educação (CBIE 2019)

Anais do XXV Workshop de Informática na Escola (WIE 2019)

\subsection{Pesquisa de Estudos Primários}

Após terem sido definidas as questões de pesquisa, definiram-se as fontes de busca. $\mathrm{O}$ mapeamento foi conduzido nas bases de dados de publicações indexadas pela Comissão Especial de Informática na Educação (CEIE), Periódicos Capes e Scopus. A string de busca foi gerada a partir do período de 2010 a 2019, e da combinação das palavras chave e foram divididas pelos idiomas da seguinte forma:

- Português: Tecnologias Digitais de Informática e Comunicação AND Estratégias de Motivação.

- Inglês: Digital Technologies of Informatics and Communication AND Motivation Strategies

A Tabela 1 apresenta a quantidade de artigos retornados em cada mecanismo de busca acadêmico.

Tabela 1. Quantidade de artigos retornados.

\begin{tabular}{ll}
\hline Mecanismo de Busca & Quantidade \\
\hline CEIE & 10 \\
Scopus & 75 \\
Periódicos CAPES & 34 \\
\hline Total & 119 \\
\hline
\end{tabular}

Os critérios de inclusão e exclusão foram definidos com base nas questões de pesquisa para tornar o resultado do mapeamento sistemático mais assertivo. Foram então definidos os seguintes critérios de inclusão: Artigos completos (foram considerados artigos com mais de 4 páginas); Estudos que relatam e descrevem TDICs e sua utilização em práticas de ensino-aprendizagem. Quanto aos critérios de exclusão, tem-se: Estudos duplicados; Artigos que não se referem ao tema abordado.

\section{Resultados e Discussões}

Nessa seção, serão abordadas as duas últimas fases deste mapeamento sistemático: extração e síntese dos dados e análise dos dados. As questões de pesquisa serão relacionadas aos trabalhos selecionados na triagem, juntamente com uma análise e discussão dos resultados.

Dos quinze artigos encontrados, com o auxílio das strings de busca, dez foram excluídos por não responderem algumas das questões de pesquisa. Os estudos incluídos na etapa anterior foram lidos, retornando 4 artigos fortemente relacionados ao tema proposto e as questões da pesquisa. Sendo utilizados para responder as questões a seguir.

\subsection{Questão 1: Qual o perfil dos professores?}

A apropriação das TDICs como recursos didáticos precisa ser construída desde a formação inicial docente. Tais ferramentas devem fazer parte da rotina dos futuros professores ainda enquanto alunos dos cursos de licenciaturas [Monteiro et al. 2015]. Por certo, a formação continuada também possui papel central em favor da disseminação das TDICs na Educação. Contudo, no atual contexto tecnológico, as Universidades, 
VIII Congresso Brasileiro de Informática na Educação (CBIE 2019)

Anais do XXV Workshop de Informática na Escola (WIE 2019)

instituições prioritariamente responsáveis pela formação desses profissionais, não podem ficar sem os benefícios das TDICs na sociedade e na educação.

A inserção e integração das TDICs na prática docente e na escola deve estar articulada com a capacitação dos professores para o exercício deste trabalho. Com as TIDCs abrem-se novas possibilidades à educação, exigindo uma nova postura do educador. Com a utilização de redes telemáticas na educação, pode-se obter informações nas fontes, como centros de pesquisa, Universidades, Bibliotecas, permitindo trabalhos em parceria com diferentes escolas; conexão com alunos e professores a qualquer hora e local, favorecendo o desenvolvimento de trabalhos com troca de informações entre escolas, estados e países, através de cartas, contos, permitindo que o professor trabalhe melhor o desenvolvimento do conhecimento [Xavier 2013].

Dessa forma, é possível o professor se transformar em um estimulador do aprendizado do aluno, despertando nele a curiosidade em conhecer, em pesquisar, e buscar a informação mais relevante. O professor deixa de ser o repassador do conhecimento para ser o criador de ambientes de aprendizagem e facilitador do processo pelo qual o aluno adquire conhecimento [Monteiro et al. 2015].

O professor que utiliza as TDICs deve possuir conhecimento do conteúdo, metodologia de ensino, saber lidar com as emoções, ter compromisso com a produção do conhecimento por meio de pesquisas e extensões e, sobretudo, romper os paradigmas das formas conservadoras de ensinar, aprender, pesquisar e avaliar com as inovações tecnológicas [Pereira and Goncalves 2017].

\subsection{Questão 2: Quais estratégias utilizando as TDICs podem ser utilizadas para melhorar o processo de ensino-aprendizagem?}

Vive-se um momento especial da história humana, um tempo de descobertas, de aberturas e evolução para o conhecimento humano. Na história da humanidade na qual o imprevisto, o novo e a mudança estão presentes a cada dia e a cada instante ao lado dos grandes avanços tecnológicos, as transformações indicam que estamos evoluindo a cada dia [Nicolau et al. 2018].

Deste modo, observam-se inúmeras transformações em todos os setores da vida humana. O progresso tecnológico é evidente, agora é possível processar, armazenar, recuperar e comunicar informação em qualquer formato, facilitando o trabalho e agilizando a comunicação em diferentes esferas. O cotidiano é influenciado pelo mundo audiovisual, na qual as Tecnologias agem diretamente no fazer e recriar. [Nunes et al. 2017]. A educação está diante de profundas mudanças sociais, culturais e tecnológicas, trazem implicações sociais na construção do conhecimento no ambiente escolar. A instituição de ensino deixou de ser o principal meio de transmissão das informações com o advento das TDICs [Nunes et al. 2017].

São tecnologias usadas para reunir, distribuir e compartilhar informações. É necessário que se pense em novas formas de agir, de interagir e que esse aprendizado contribua na inserção dos jovens no mercado de trabalho. A presença constante da tecnologia na sociedade justifica que haja a presença deste mecanismo também na escola [Nicolau et al. 2018].

No processo de ensino-aprendizagem é importante destacar a importância do 
VIII Congresso Brasileiro de Informática na Educação (CBIE 2019)

Anais do XXV Workshop de Informática na Escola (WIE 2019)

aprender fazendo, do aprender a aprender, do interesse, da experiência e da participação como base para a vida em uma democracia. As modernas pedagogias têm apontado na direção da aprendizagem ativa, do trabalho coletivo, da participação, da pesquisa e da construção do conhecimento [Xavier 2013].

\section{Conclusão}

Sabendo que a iniciação do docente poderá deparar-se com um novo perfil de aluno e uma escola imersa na cultura digital, envolvendo o uso de recursos tecnológicos na sala de aula, coloca-se que a formação inicial de professores deve oferecer não apenas condições de aplicar o conteúdo, mas também que as TDICs e a prática pedagógica tenham domínio e a prática na operação dos recursos digitais.

Conclui-se então que tais recursos educativos possuem um vasto potencial de uso na educação, em especial na formação docente. Questões como a facilidade de acesso e ambiente colaborativo permitem que se crie uma experiência de ensino-aprendizagem com mais eficácia. Na formação de professores em especial, as TDICs podem melhorar significativamente a ação pedagógica, uma vez que não apenas inserem novos dispositivos que facilitam e dinamizam o processo de ensino-aprendizagem

Nessa perspectiva, pode-se observar a potencialidade das TDICs como recurso para a formação continuada tanto de professores como de alunos. E essa possibilidade de aprendizagem contínua revela a perspectiva de construção continuada da educação na utilização das TDICs no processo de ensino-aprendizagem.

\section{Referências}

Farias, L. C. and Dias, R. E. (2013). Discursos sobre o uso das tdics na educação em documentos ibero-americanos. Revista Linhas, 14(27):83-104.

Monteiro, J., Pires, G., Lima, D., Rego, L., and Maia, D. (2015). Formação inicial docente para as tdic: Análise a partir do curso de pedagogia do campus central da ufrn. In Anais do Workshop de Informática na Escola, volume 21, pages 454-465.

Nicolau, R., Pessoa, G., and Costa, F. (2018). Que professor teremos na escola brasileira: nativo, imigrante ou e-migrante digital? In Anais do Workshop de Informática na Escola, volume 24, page 558.

Nunes, L. L. d. S. T., da Rosa, L. Q., de Souza, M. V., and Spanhol, F. J. (2017). Educação em rede: tendências tecnológicas e pedagógicas na sociedade em rede. EmRede-Revista de Educação a Distância, 3(2):197-212.

Pereira, J. and Goncalves, M. R. B. (2017). Tecnologias digitais da informação e comunicação na extensão universitária: Projeto redação enem. In Anais do Workshop de Informática na Escola, volume 23, page 98.

Xavier, A. C. (2013). Educação, tecnologia e inovação: o desafio da aprendizagem hipertextualizada na escola contemporânea. Revista (Con) textos Linguísticos, 7(8.1):42-61. 